\title{
Sounding rocket experiment of bare electrodynamic tether system
}

\author{
Hironori A. Fujii ${ }^{\mathrm{a}}$, Takeo Watanabe ${ }^{\mathrm{b}, *}$, Hirohisa Kojima ${ }^{\mathrm{b}}$, Koh-Ichiro Oyama $^{\mathrm{b}}$, \\ Tairo Kusagaya ${ }^{\mathrm{c}}$, Yoshiki Yamagiwa ${ }^{\mathrm{d}}$, Hirotaka Ohtsu ${ }^{\mathrm{d}}$, Mengu Cho ${ }^{\mathrm{e}}$, Susumu Sasaki ${ }^{\mathrm{f}}$, \\ Koji Tanaka ${ }^{\mathrm{f}}$, John Williams ${ }^{\mathrm{g}}$, Binyamin Rubin ${ }^{\mathrm{g}}$, Charles Les Johnson ${ }^{\mathrm{h}}$, \\ George Khazanov $^{\mathrm{h}}$, Juan R. Sanmartin ${ }^{\mathrm{i}}$, Jean-Pierre Lebreton ${ }^{\mathrm{j}}$, Erick J. van der Heide ${ }^{\mathrm{k}}$, \\ Michiel Kruijff $^{\mathrm{k}}$, Fabio De Pascal ${ }^{\mathrm{k}}$, Pavel M. Trivailo ${ }^{1}$ \\ ${ }^{a}$ Kanagawa Institute of Technology, Atsugi, Kanagawa 243-0292, Japan \\ ${ }^{\mathrm{b}}$ Department of Aerospace Engineering, Tokyo Metropolitan University, 6-6, Asahigaoka, Hino, Tokyo 191-0065, Japan \\ ${ }^{\mathrm{c}}$ Airship Technology and Survey Technology Institute, Japan \\ ${ }^{\mathrm{d}}$ Shizuoka University, Shizuoka 432-8561, Japan \\ ${ }^{\mathrm{e}}$ Kyusyu Institute of Technology, Kitakyusyu 804-8550, Japan \\ f JAXA/ISAS, Sagamihara, Kanagawa 229-0022, Japan \\ g Colorado State University, Fort Collins, CO 80523, USA \\ $\mathrm{h}_{\text {NASA, George C. Marshall Space Flight Center }}$ \\ ${ }^{\mathrm{i}}$ Universidad Politecnica de Madrid, Madrid 28040, Spain \\ $\mathrm{j}_{\text {ESA/ESTEC, Noordwijk, Netherlands }}$ \\ ${ }^{\mathrm{k}}$ Delta Utec, 2312 TT Leiden, Netherlands \\ ${ }^{1}$ RMIT University, Bundoora VIC 3083, Australia
}

Received 21 December 2007; received in revised form 15 June 2008; accepted 2 July 2008

Available online 3 September 2008

\begin{abstract}
An overview of a sounding rocket, S-520-25th, project on space tether technology experiment is presented. The project is prepared by an international research group consisting of Japanese, European, American, and Australian researchers. The sounding rocket will be assembled by the ISAS/JAXA and will be launched in the summer of 2009. The sounding rocket mission includes two engineering experiments and two scientific experiments. These experiments consist of the deployment of bare electrodynamic tape tether in space, a quick ignition test of hollow cathode system in space, the demonstration of bare electrodynamic tether system in space, and the test of the OML (orbital-motion-limit) current collection theory.
\end{abstract}

(c) 2008 Elsevier Ltd. All rights reserved.

Keywords: Electrodynamic tether; Tape tether; Sounding rocket; OML theory

\footnotetext{
* Corresponding author. Tel.: +81425858694; fax: +81425835119 .

E-mail addresses: fujii@eng.kanagawa-it.ac.jp (H.A. Fujii), nabetake@sd.tmu.ac.jp (T. Watanabe), hkojima@sd.tmu.ac.jp (H. Kojima), kohichiro@yahoo.co.jp (K.-I. Oyama),pdf02776@nifty.com (T. Kusagaya),tmyyama@ipc.shizuoka.ac.jp (Y. Yamagiwa), thoots@ipc.shizuoka.ac.jp (H. Ohtsu), cho@ele.kyutech.ac.jp (M. Cho), sasaki@isas.jaxa.jp (S. Sasaki), tanaka@isas.jaxa.jp (K. Tanaka), john.d.williams@colostate.edu (J. Williams), brubin@engr.colostate.edu (B. Rubin), les.johnson@msfc.nasa.gov (C.L. Johnson), George.V.Khazanov@nasa.gov (G. Khazanov), juanr.sanmartin@upm.es (J.R. Sanmartin), jplebret@rssd.esa.int (J.-P. Lebreton), Erik@delta-utec.com (E.J. van der Heide), Michiel@delta-utec.com (M. Kruijff), fabio@ fabiolinux.com (F. De Pascal), trivailo@rmit.edu.au (P.M. Trivailo).
} 


\section{Introduction}

Space tether technology is expected to be one of the promising technologies to enable the activity of human in space to construct space infrastructures since it provides simple, light weight, and compact elements to be constructed in an autonomous manner and also a variety of uses for scientific and engineering purposes [1].

A space tether experiment is proposed to deploy a $300 \mathrm{~m}$ bare electrodynamic tape tether in order to conduct two scientific experiments as the first ever attempt in the world by an international team consisting of Japanese, European, American, and Australian tether enthusiasts. The sounding rocket will be prepared by the ISAS/JAXA and will be launched in summer of 2009 [2].

The sounding rocket is employed as a reasonable solution for the demonstration mission of the space tape tether technology. Previous tether related experiments onboard of a sounding rockets have been performed by the Canadian Space Agency (Oedipus A and C) and NASA/Japan (CHARGE-1 and 2) [3]. The Oedipus mission composed of two identical sub-payloads separated by a $1-\mathrm{km}$ insulated conducting tether line and the subsatellites were spun about their longitudinal axis (along the tether line) and the mission was mainly meant to study the plasma characteristics of the Aurora lights. The flight duration was about $15 \mathrm{~min}$. The earlier CHARGE experiments were designed to study the interaction between electron beam emissions and electrical charging of the satellite. The release of neutral gas for charging mitigation was one of the other interesting experiments [4].

The object of the present tether experiment is to verify the performance of bare electrodynamic tether (EDT) in space $[5,6]$.

This experiment of a bare EDT had been planned once by NASA as the ProSeds experiment, which was eventually cancelled due to the accident of the space shuttle "Columbia". Thus, the present experiment is now attracting international interests as the first experiment on to the EDT technology.

The present sounding rocket experiments consist of two engineering and two scientific main objectives as follows:

(1) The quick deployment of bare electrodynamic tape tether in space: engineering experiment-I.

(2) The quick ignition test of hollow cathode system in space: engineering experiment-II.
(3) The demonstration of the operation of a bare electrodynamic tether (EDT) system in space: science experiment-I.

(4) Testing of the OML (orbital-motion-limit) current collection theory: science experiment-II.

These engineering and scientific demonstrations could open a door for the bare EDT, which has a variety of applications in space infrastructures including as an engine to increase/decrease orbit, an accelerator and ejector for payload, and an electric power supplier $[7,8]$. The experiment will also be an extremely effective demonstration to examine the application of the rotating EDT to Jupiter mission in order to enable simple entry into the atmosphere of the Jupiter without the loss of fuel. The drivers for the EDT are underlying with a low cost, simple mission concept, and fast realization possibility.

This section has described the overview of the S-520-25th sounding rocket experiment. The next section presents the time sequence of the mission, and Section 3 shows the overviews of experiments, and their configuration.

\section{Sequence of the flight operation}

The time sequence of the S-520-25th flight operation is shown in Fig. 1. The primary goal of the mission is the extremely quick deployment of the bare tape tether, which starts after burn out time of the S-520, i.e., 30 s after launch.

After the opening of nose cone at the altitude of $70 \mathrm{~km}$, the daughter payload (DAU) is ejected forward in the flight direction, resulting in the deployment of the bare tape tether from the Mother Payload (MOT) on the rocket body. The deployment time of the $300 \mathrm{~m}$ tape tether corresponds approximately to $120 \mathrm{~s}$ immediately after the ejection of the tethered DAU.

The second goal of the experiment is the quick ignition of the hollow cathode, the engineering experimentII. The hollow cathode component, which is designed to satisfy quick ignition, and named "FAST (fast starting hollow cathode test pallet)" is developed by Colorado State University (CSU). The deployment of the tape tether will be completed in approximately $180 \mathrm{~s}$ from the launch, and then, the FAST hollow cathode will be ignited also.

Immediately after these two engineering experiments are completed, the stage of the scientific experiments will be carried out. During this stage two scientific experiments (demonstration of EDT system, and verification of OML theory) will be conducted in the remaining time of the ballistic flight. 


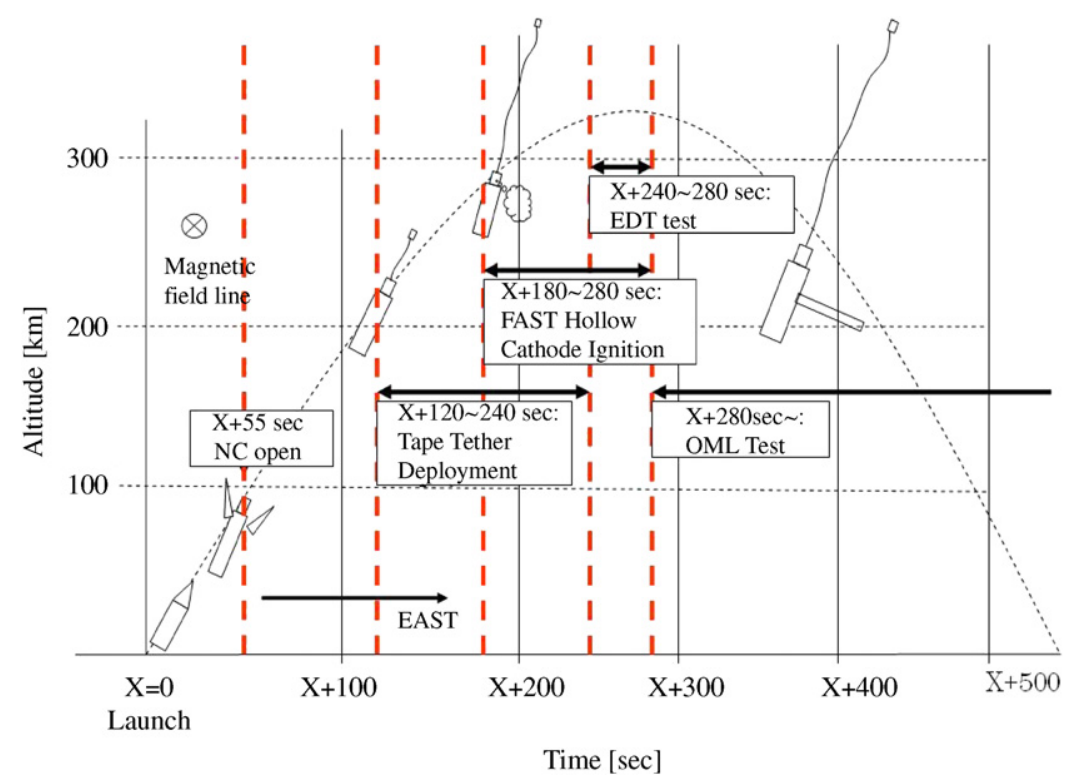

Fig. 1. Time sequence of the S-520-25th sounding rocket flight operation.

During the scientific experiment-I, the negative terminal of the power supply is switched to be connected to a cathode device (a hollow cathode), and the positive terminal is connected to the tape tether. Electrons collected by the tape tether cross the supply and are ejected at the hollow cathode. The current loop between EDT and the ambient plasma is formed by this procedure, and it will verify the current flow in EDT, then the EDT operation and the effective current collection by bare tape tether.

Test of the OML theory is a demonstration by the use of bare tether by collecting electrons on the bare EDT.

In order to verify the OML theory that explains electron and ion collection using a boom and a bare tether, a bare tape tether and a low plasma density is appropriate. Although a sufficient level of plasma density is necessary for the test of the operation of EDT system, the induced electrical magnetic force for the ballistic flight is low because of the low speed of the sounding rocket payloads. Therefore, a bias voltage about $1 \mathrm{kV}$ has to be supplied in order to study the collection of electrons on the passive bare tether.

Based on these requirements, the rocket has to be launched at dawn. Scientific missions also require the launch to be at the middle latitude area of the Earth with the Earth dipole angle (dip) between $\frac{1}{2}<\tan (\mathrm{dip})<2$ and the Japanese launch site is appropriate for this requirement. The length and the width of the tape tether were selected based on the theoretical requirements to the boundary of the collecting surface for the most optimal electrical performance of the system. The sounding rocket S520 has a much higher apogee and flight duration and it was decided for the present mission to launch the $70 \mathrm{~kg}$ payload at an altitude of $300 \mathrm{~km}$.

\section{Engineering and scientific experiments}

\subsection{Quick deployment of the tape tether}

No retrieval is necessary in the present mission and for the present project it is necessary only to deploy the tape tether at a relatively quick speed, i.e., $300 \mathrm{~m}$ in a few minutes. A space tether is usually deployed from a spool by controlling the tension in unwound section. Deployment of the tape tether should be sufficiently swift and highly reliable in the present sounding rocket experiment, which will be conducted in a short period of time. A new method was thus devised for the tape tether deployment employing a method of folding tapes [9]. Some numerical simulations and experiments for verification of performance are studied to confirm the performance.

The usual strand tether deployers can be classified into the Tethered Satellite System (TSS) series type reel systems [10] and Small Expendable Deployer System (SEDS) type fixed spool systems [11]. The TSS type deployer can control both deployment and retrieval of the tether system by driving motorized reel, but the use of active control devices increases the complexity of system dramatically. The SEDS type fixed spool type 


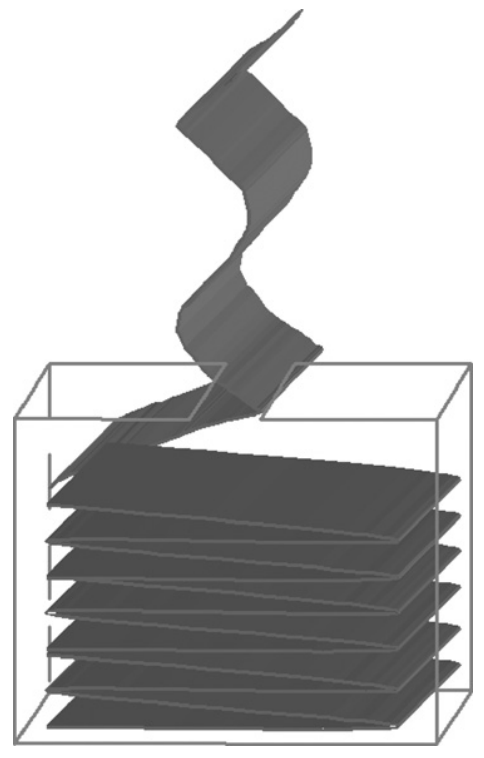

Fig. 2. Folded tape (z-fold).

deployer can be used only for deployment of the tether, and it can be designed in simpler configuration. The fixed spool type deployer was controlled by the brake system. Several missions of such a strand tether deployer have been conducted in orbit or proposed.

There are a few studies concerning the tape tether deployment. The Delfi-1 project by the Delft University of Technology team tried to develop a tape tether deployer which employs movie reel type deployer for the tape tether [12] in which stored tape tether is wound around a reel. The ATEx deployer [13] used a motorized constant winding reel and tape tether of $6 \mathrm{~km}$ in length, ATEx had been designed to complete the deployment of the tether in several days.

Quick deployment of the tape tether is prepared by the staff of TMU/TMIT. The present mission requires a reliable and robust deployer because the bare tape tether is shown to have many unknown dynamic characteristics and a complex dynamic behavior. The deployment system employs a foldaway storage method. The present foldaway tape tether deployer (FTD) is based on a new concept (Fig. 2) and is totally different from the usual reel type tether deployers (RTD), This innovative storage method is a key idea of the proposal to satisfy the requirements of the science mission. The features of the FTD can be described as follows:

(1) High reliability when compared to the RTD: Particularly, it has a small probability of malfunctioning in quick deployment because the effects of the

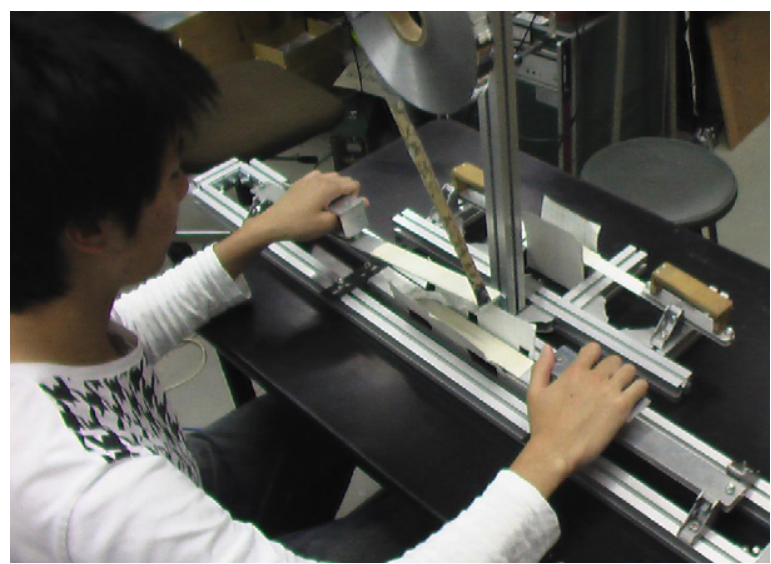

Fig. 3. Semi-automatic folding mechanism.

inertia are very small in comparison with the RTD type.

(2) Simplicity of the mechanism: The system consists of a few parts and has no movable component devices.

Each folding point has the memory shape ability and estimations of the dynamic/electric performance of the material are necessary concerning to the folding points.

Fig. 3 shows a semi-automatic foldaway machine. It takes approximately $1 \mathrm{~m}$ per minute to fold the tape with the developed foldaway machine.

The payload of the sounding rocket consists of the DAU, Tether Deployment System, Scientific Measurement Devices, Hollow Cathode Unit (FAST), and a battery as shown in Fig. 4. Preliminary design of the tether deployment is shown in Fig. 5. In order to remove any effects of contaminations, the initial velocity of the deployment is given by the kinetic energy of loaded springs installed on the ejector with long stroke guide shafts. The deployment sequence was designed, as shown in Fig. 6 under the constraints of the system, including tape tether toughness, and structural load constraints. The initial velocity is given to the DAU to deploy the tape tether, and at the end of the deployment, the DAU should be carefully decelerated by the brake in order to stop it and not to bounce back. The brake system is designed to generate optimal force by the friction of brake pad. The cameras and the GPS receivers are installed on the MOT and the DAU, respectively, in order to observe the dynamics of tether deployment.

In order to confirm the reliability of the spring ejection mechanism and stability of tether in the deployment phase, the following three preliminary tests were conducted as a qualitative analysis. 


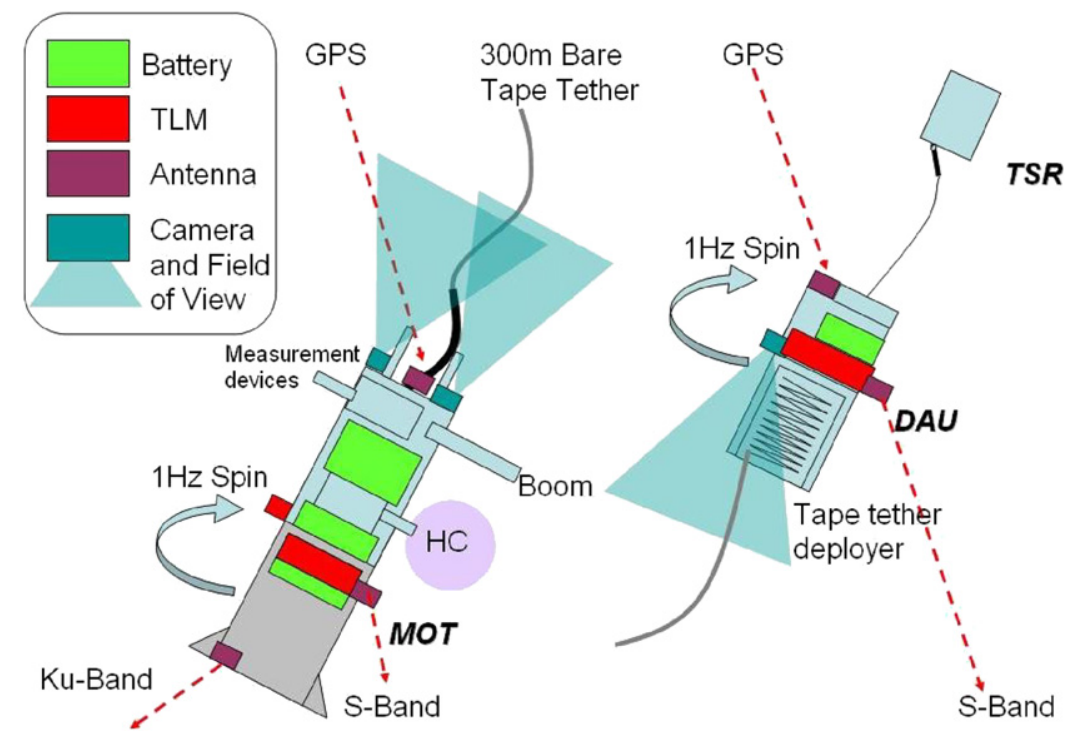

Fig. 4. Primary design of the payload.

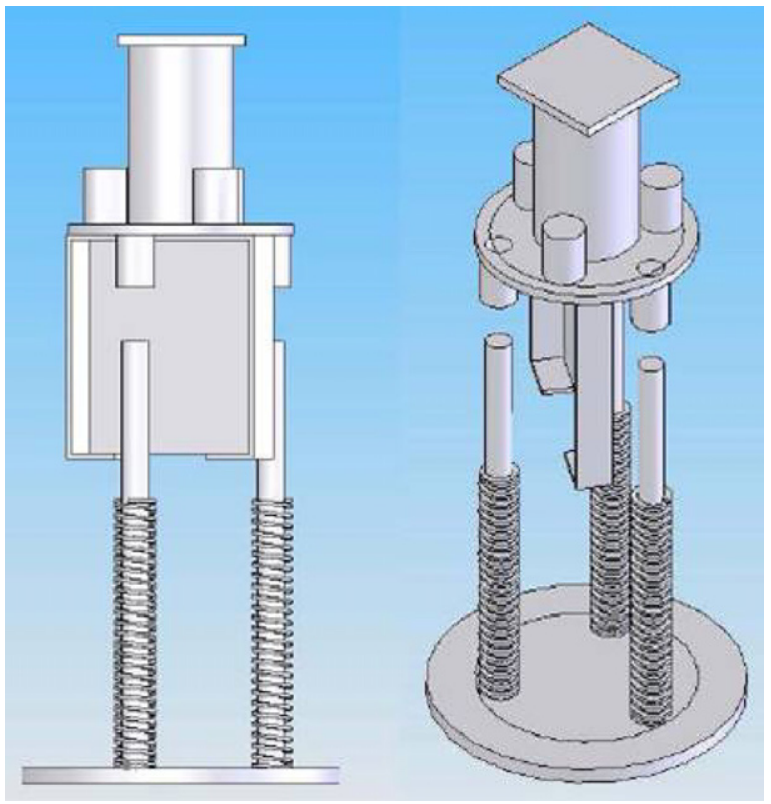

Fig. 5. Concept of the ejection system.

\subsubsection{Tether deployment demonstration using water rocket model}

The deployment behavior of the tape tether deployer was tested using a water rocket model. The specifications of the test are listed in Table 1. The mass of the end mass and spring for ejection were determined to adjust the scale similarities of the water rocket to a real rocket as much as possible, apart from the parameters of the tape tether. The spring was set in the rocket model to eject the end mass, and a wire was set between the end mass the water rocket model to hold the compressed springs. A small on-board electric circuit was manufactured and installed in the rocket model to count the mission time and to send the wire cutting command to the ejector. Fig. 7 shows a result of one of the test demonstrations. The wire cutter cut the holding wire by burning the wire during the flight of the water rocket. The end mass was ejected by the spring force, then the tape tether was successfully deployed. The water rocket tests showed the reliability of the foldaway tape tether deployment in the ballistic flight.

\subsubsection{Tether deployment test in micro-gravity condition}

In the project, the rocket attitude stabilization is almost always realized by the spin stabilization method. Therefore, it is necessary to study whether the tape tether is successfully deployed from the rotating rocket. The deployment of the tape tether from a rotating base under a micro-gravity condition was examined using airplane ballistic fights provided by Diamond Air Service Inc. The specifications of the test condition are listed in Table 2. The mass of DAU, the tether length, and the initial velocity were restricted by the available space for safe experiment in the airplane. The spin rate was set to the predicted spin rate of the sounding rocket. The deployment behavior of the folded tether was observed and filmed. Fig. 8 shows one of the results of deployment phase experiment. The DAU model flew from the 

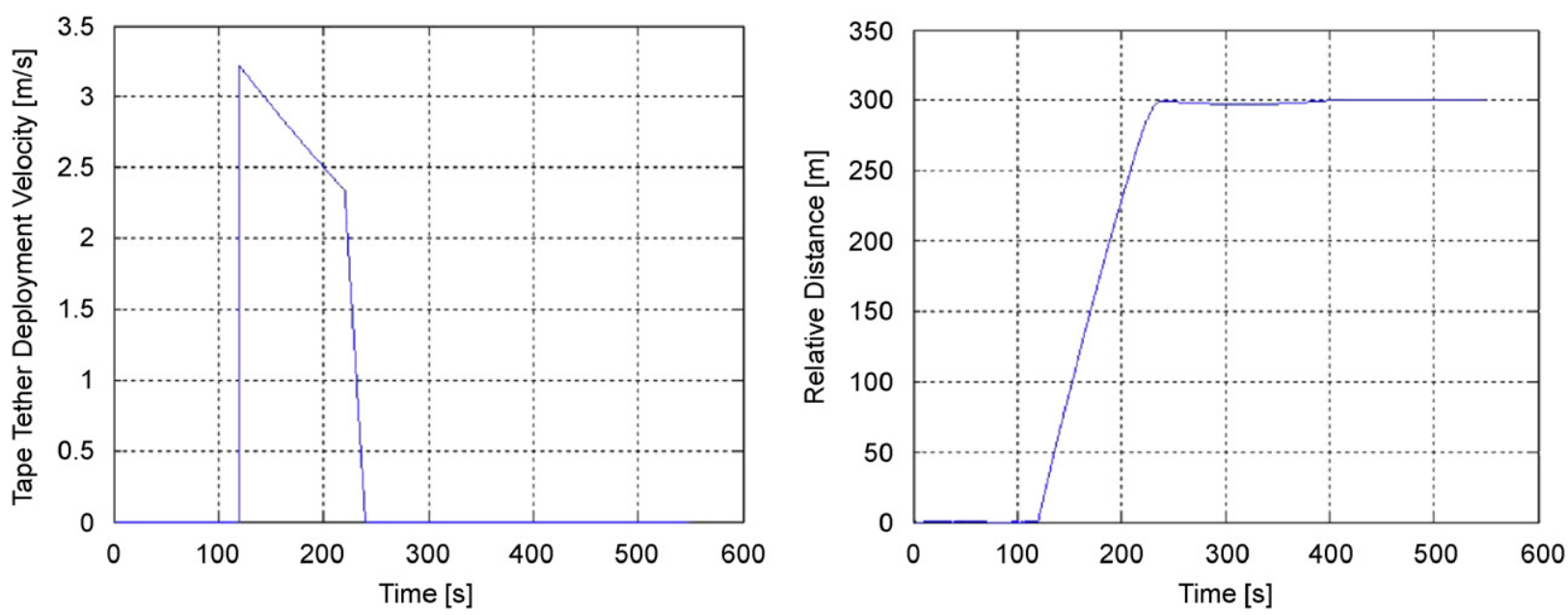

Fig. 6. Example of the deployment design (left: velocity, right: length).

Table 1

Specifications of the water rocket tests .

\begin{tabular}{lll}
\hline Tape tether & ALPET & $\# 101210$ \\
& Thickness & $35 \mu \mathrm{m}$ \\
& Width & $6 \mathrm{~mm}$ \\
& Length & $8 \mathrm{~m}$ \\
& Fold pitch & $80 \mathrm{~mm}$ \\
End mass & Mass & $130 \mathrm{~g}$ \\
Ejector & Spring coefficient & $16 \mathrm{~N} / \mathrm{mm}$ \\
& Load & $800 \mathrm{~N}$ (total) \\
\hline
\end{tabular}

rotating launcher, the rotational motion of the DAU was kept and no twist was observed along the tether during the present deployment test. The experimental results demonstrated the performance of the present deployment system with reliability in the micro-gravity environment. The deployment length was, however, quite a lot shorter than that of the real project. Thus, the deployment behavior will have to be studied further for the case of long tether in the next step.

\subsubsection{Braking system}

A simple feed forward brake system is desired for the tape tether deployment, because it is not easy to measure the deployed tether length and its velocity precisely. Fig. 9 shows the design of the braking system, which contains a pair of brake pads. One braking pad is held and other braking pad is attached to a bush through the shaft and allowed to move. The load is applied to the brake pads by means of a compressed spring and held by a holder through the shaft. To smoothly deploy the tape tether, the shape of the braking pads are made round and two guides are placed beneath the pads. To effectively decelerate the speed around the end of deployment, the tape tether storage with two stages is designed, as shown in Fig. 10. The first stage is a part of tape tether deployment and the second stage is a braking part. The required braking drag force and the length of tape tether in the second stage will be predicted, based on the drag coefficient measured in vacuum environment.

\subsection{FAST ignition}

The present sounding rocket experiment requires a plasma device (a plasma contactor) to produce a low impedance connection between the space plasma and the MOT end of the tether. The electrical connection to the space plasma will allow electrical biases to be applied to the tether enabling the investigation of electron collection on the tether versus bias. Due to the short time duration of the sounding rocket mission, the plasma contactor will need to become operational within $180 \mathrm{~s}$ after launch using a minimal amount of electrical power. It is noted that conventional power efficient plasma devices can sometimes require tens of minutes or more to become operational. This is longer than a typical sounding rocket flights of $6-10 \mathrm{~min}$. The goal of the plasma contactor system development effort described herein is to design, analyze, and fabricate all of the sub-systems and ground-support equipment that are required to quickly start and operate a plasma contactor. In addition, this task includes integration of the sub-systems 


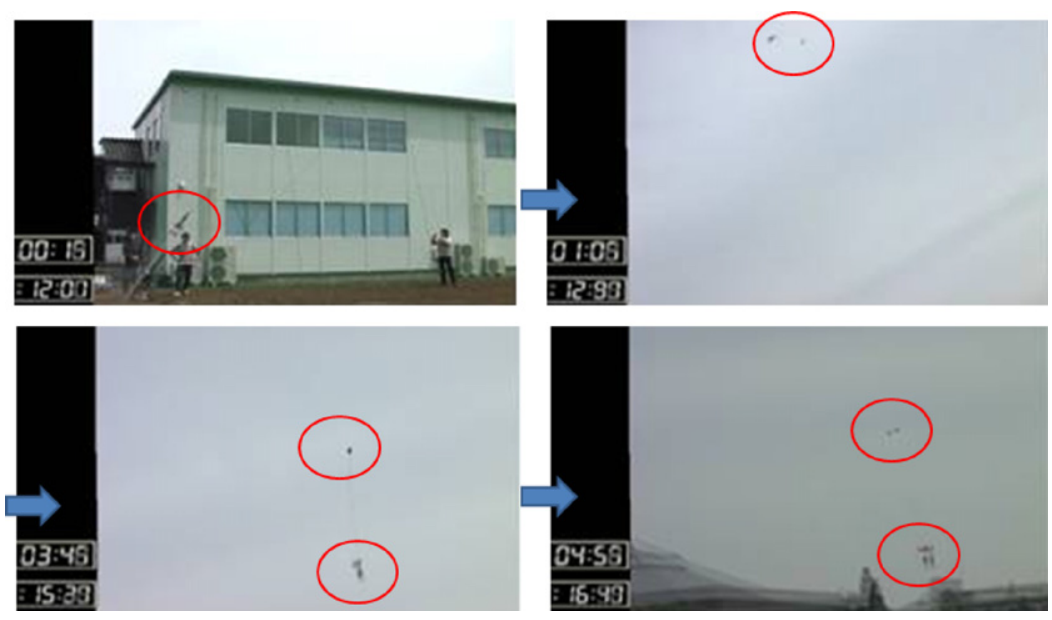

Fig. 7. Tape tether deployment test using a water rocket model.

Table 2

Specifications of Launch phase experiment.

\begin{tabular}{ll}
\hline Tether length & $2.15 \mathrm{~m}$ \\
Foldaway pitch & $100 \mathrm{~mm}$ \\
Tether width & $20 \mathrm{~mm}$ \\
Mass of DAU & $1.2 \mathrm{~kg}$ \\
Initial velocity & $0.5 \mathrm{~m} / \mathrm{s}$ \\
Spin rate & $1 \mathrm{~Hz}$ \\
\hline
\end{tabular}

into a system that is self-contained, autonomous, and straightforward to mate to the sounding rocket payload. Critical supporting sub-systems include gas storage and delivery, power conditioning and delivery, transducers and sensors, and a micro-controller as shown in the sketch in Fig. 11. Conceptual views of a plasma contactor system are shown in Fig. 12, and a photograph of a prototype system built at CSU is shown in Fig. 13.

The gas delivery sub-system consists of several components including a fill and drain valve that is accessible from the outside of the test pallet. This component is used in ground support operations to fill a gas tank with high purity xenon gas prior to launch. The fill and drain valve is connected to a manifold where the gas tank is attached. Also attached to the manifold is a highpressure transducer. Xenon gas is fed from the manifold to a latch valve and then to a pressure-reducing regulator. A solenoid valve is placed downstream of the regulator along with a flow-restricting element. Tubing is used to connect the flow restrictor to the hollow cathode. An additional pressure transducer is used to autonomously determine when the atmospheric pressure is reduced to the point where gas purging operations can be performed prior to initiating start up of the hollow cathode. All of the gas delivery component operation and monitoring is performed by a micro-controller embedded within an electronics sub-assembly. DC-to-DC converters are used to operate the solenoid valves and provide power to the micro-controller, transducers, and sensors.

The electronics sub-system includes connectors for ground support equipment (GSE) access to the test pallet. Separate DC-to-DC converters are used to provide power to the heater and plasma ignition elements of the plasma device, which are turned on and off with the micro-controller. A pulse-width modulation approach is used to control heater power application and the accelerated conditioning process.

The approximate sequence of the FAST pallet system activation process is presented in Table 3 [14].

\subsection{Demonstration of EDT system}

After the operation of hollow cathode becomes stable, the demonstration of EDT operation is performed by applying the positive bias voltage $(\sim 1 \mathrm{kV})$ on bare tape tether and the negative bias voltage on hollow cathode (Fig. 14).

Electrons collected by the tape tether cross the supply and are ejected at the hollow cathode. The current loop between EDT and the ambient plasma is formed by this, and the current flow in EDT, then the EDT operation and the effective current collection by bare tape tether will be verified.

It is considered that the electron collection by a bare tape also will be governed by the OML theory. It is 

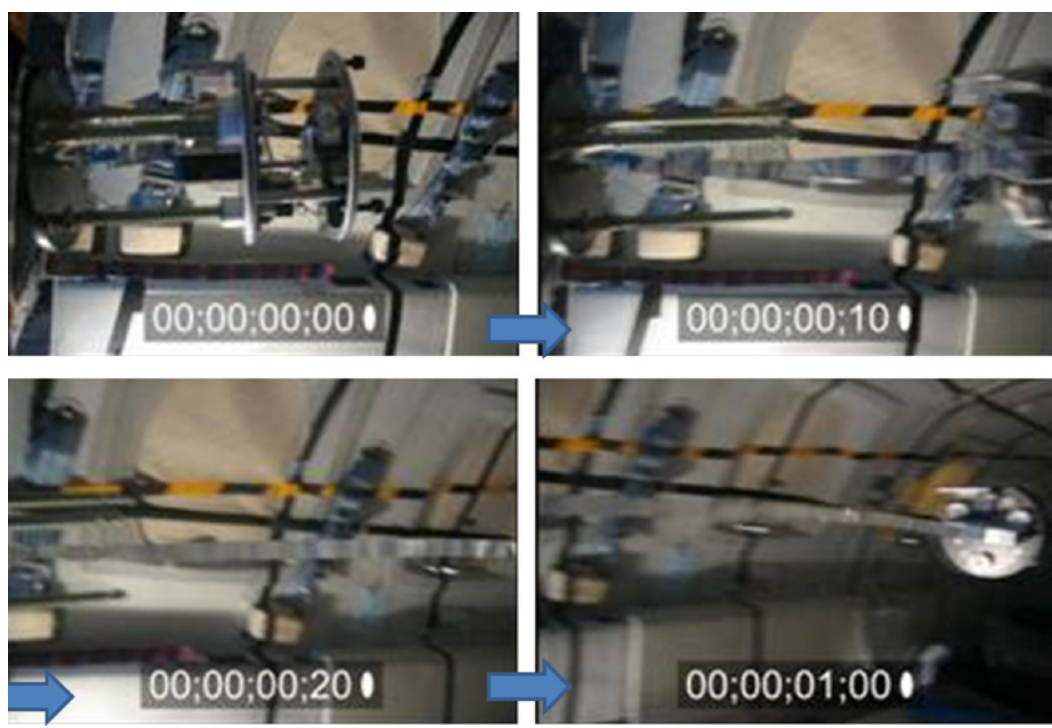

Fig. 8. Test of tape tether deployment and ejection of the DAU from the rotating base in the micro-gravity condition.

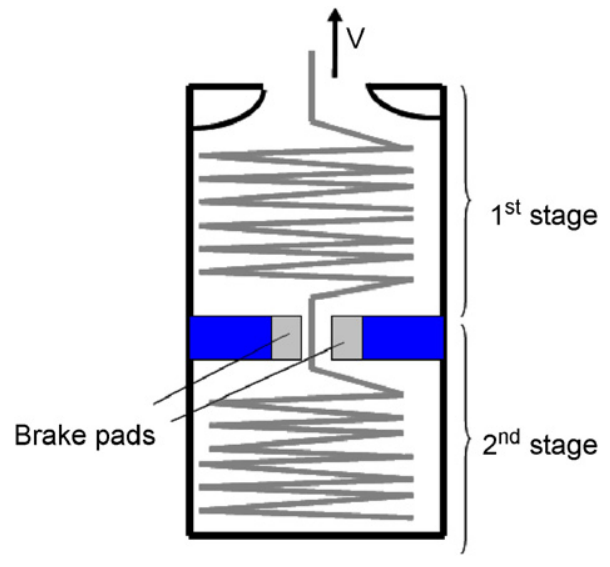

Fig. 9. Tether storage configuration for passive control of deployment velocity.

possible to verify the electron collection theory by a bare tape tether in space by changing the applied voltage on bare tape tether in this phase. The electron current collected by bare tether follows the following equation obtained from OML theory,

$I_{\mathrm{e}}($ tape $)=e N_{\infty} L_{\mathrm{t}} \frac{2 w_{\mathrm{t}}}{\pi} \sqrt{\frac{2 e \varepsilon}{m_{\mathrm{e}}}}$

where $e=1.6 \times 10^{-19} \mathrm{C}, N_{\infty} \simeq 10^{12} \mathrm{~m}^{-3}$ (at $300 \mathrm{~km}), L_{\mathrm{t}}=300 \mathrm{~m}, w_{\mathrm{t}}=25 \mathrm{~mm}$, and $m_{\mathrm{e}}=9.1 \times$ $10^{-31} \mathrm{~kg}$ are electric charge, plasma density, tether length, tether width, and mass of electron, respectively.

The applied voltage $\varepsilon$ would be swept over a range of values, corresponding to different bias shots, from 0.1 to $1 \mathrm{kV}$ per $0.1 \mathrm{kV}$ at every $2 \mathrm{~s}$. The maximum current will be $1 \mathrm{~A}$ at $1 \mathrm{kV}$, so the maximum required battery power is $1 \mathrm{~kW}$.

Total experiment time is $40 \mathrm{~s}$ starting $240 \mathrm{~s}$ after the launch and finishing after $280 \mathrm{~s}$ when the hollow cathode shuts down. The temperature increase will be critical for the experiment since the tape will collect electrons but will not affect the tape material since the time period of the high voltage is too short.

\subsection{Verification of OML current collection in orbit by tape tether and boom}

The science experiment-II is a test of OML current collection in orbit. The OML theory constructed in the 1920s must be confirmed for the conditions of an orbiting tether in LEO. The test was expected to be carried out in the Pro-SEDS project, which was canceled due to the possibility of hazardous collision with the International Space Station. The present experiment will thus be the first OML experiment in space [15].

The current collection by probe is explained by Langmuir theory when the representative length of the probe (radius for cylinder) is larger than the Debye length of the surrounding plasma and the (maximum) collected 

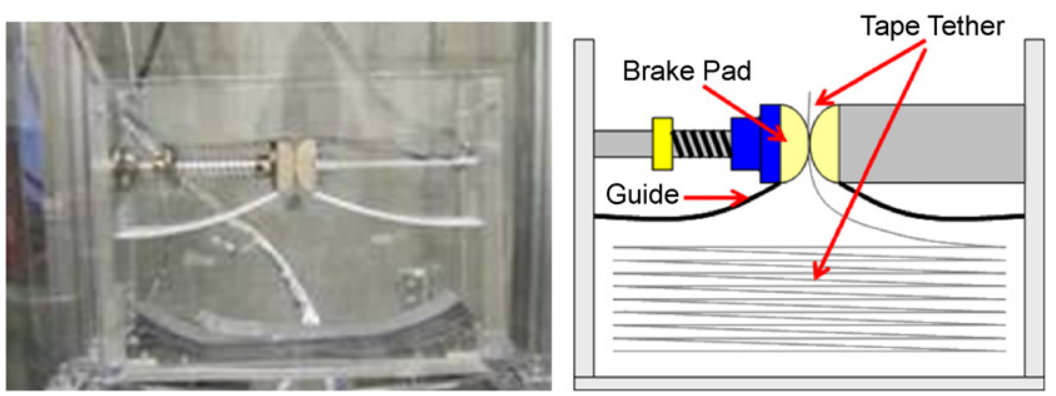

Fig. 10. Schematic representation of the braking system.

current only depends on electron temperature and density of the surrounding plasma. However, the representative length of the probe is almost equivalent to or is smaller than the Debye length, OML theory is applied for the current collection by probe. The collected current also depends on the potential difference between the probe and the surrounding plasma in addition to plasma density. The current value obtained by OML theory will be larger than that obtained by Langmuir theory. The maximum collected current by OML theory is determined by the orbital motion theory of charged particle near the probe and the collected current decreases with increasing the ratio of the representative length of the probe to the Debye length. OML theory has been tested on the ground by many researchers, but has not been tested yet in orbit and this tether rocket experiment will be the first case of the verification of OML current collection theory in orbit. The experiment of current collection in plasma in orbit with the existence of the fast relative velocity between the probe and the surrounding plasma under the geomagnetic field will not only give the new knowledge in plasma physics, but will be also very important for the understanding of the charging phenomenon of spaceship and the design of the tether system which is expected for the operational system of the propulsion and power generator in space in near future.

In this experiment, the verification of electron and ion current collections theory is over a wide range, from the out of the OML regime to in the OML regime makes possible to collect the data. The point of the experiment is to compare the ratio of the representative length of the probe to the Debye length of the surrounding plasma with changing the altitude (and changing the Debye length) from 300 to $100 \mathrm{~km}$. The tape tether and the boom of fixed dimension are employed and the positive and negative bias voltage are applied (Fig. 15).

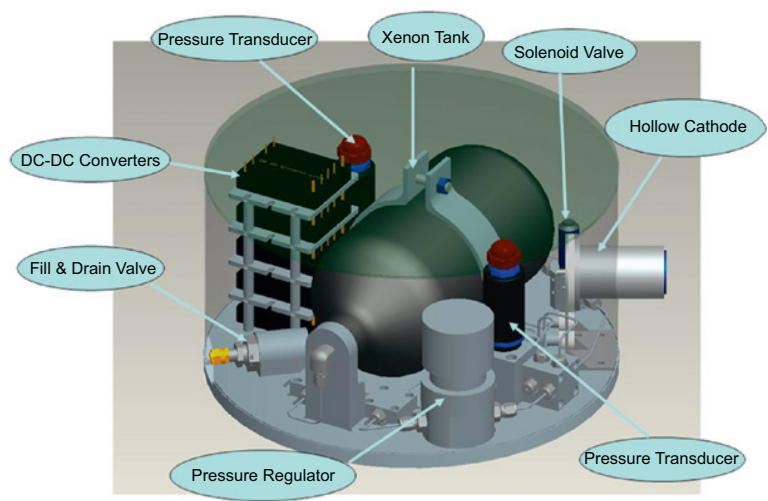

Fig. 11. Plasma contactor system layout. Note that gas lines and wiring have been omitted for clarity and the top plate and sidewall are shown semi-transparent.

With regard to the OML current collection, each cylindrical cross section can be characterized by an “equivalent" radius $R_{\text {eq }}$. Due to mass and volume restrictions, the value $R_{\text {eq }}$ of the boom should be at least 3 times larger than the Debye length at the night plasma density $(7-9 \mathrm{~mm})$ to verify the current law beyond the OML regime; the particular boom cross section being selected from a family of boom sizes. $R_{\text {eq }}$ for the tape should be about or less than the Debye length, thus within the OML regime; this means tape width about $30 \mathrm{~mm}$.

Before the start of the experiment, the boom is deployed to a length of $2 \mathrm{~m}$. The boom can be rolled flat on a drum when stored, and becomes a rigid, hollow beam when deployed. This technology has been well validated in orbit; the boom can be provided, with European support, by any European firm with experience in this kind of device. Collected electrons or ions can be measured by applying different values of electromotive force as shown in Fig. 15. 

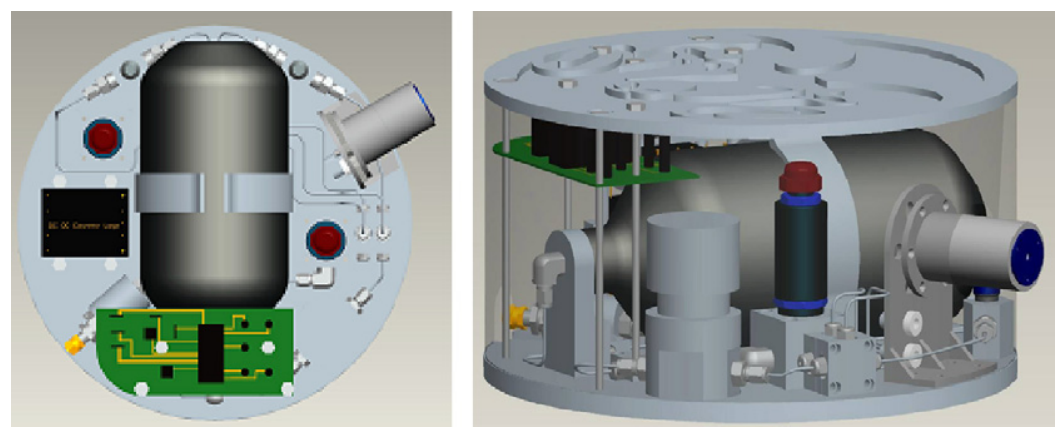

Fig. 12. Fast starting hollow cathode test pallet.

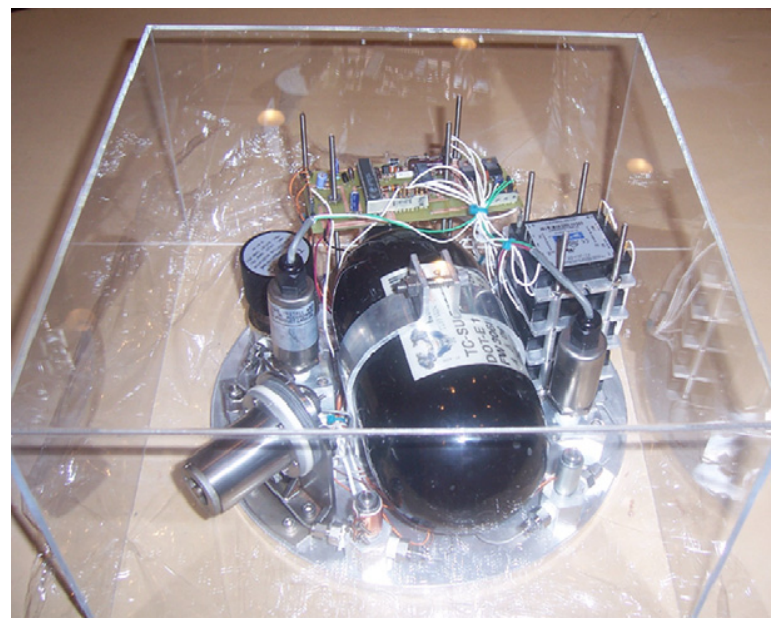

Fig. 13. Prototype plasma contactor system built at CSU.

In the first stage of the experiment, the positive terminal of power supply is the round conductive boom with length $L_{\mathrm{b}} \simeq 2 \mathrm{~m}$ and the negative terminal of power supply the tape tether with width $w_{\mathrm{t}} \simeq 25 \mathrm{~mm}$. Electrons collected by the boom cross the supply to tape, where they leak out at the rate of ion impact plus secondary yield $I_{\mathrm{e}}($ boom $)=I_{\mathrm{i}}($ tape $) \times(1+\gamma \alpha \varepsilon)$ where $\gamma \alpha \varepsilon \simeq 0.15 \mathrm{e} / \mathrm{kV}$ ion and the following equation would apply in case both boom and tape collected OML current $(\alpha<1)$ :

$$
\begin{aligned}
e & N_{\infty} L_{\mathrm{b}} 2 R_{\mathrm{b}} \sqrt{\frac{2 e(1-\alpha) \varepsilon}{m_{\mathrm{e}}}} \\
& =e N_{\infty} L_{\mathrm{t}} \frac{2 w_{\mathrm{t}}}{\pi} \sqrt{\frac{2 e \alpha \varepsilon}{m_{\mathrm{i}}}} \times(1+\gamma \alpha \varepsilon)
\end{aligned}
$$

where $R_{\mathrm{b}} \simeq 20 \mathrm{~mm}$ and $m_{\mathrm{i}}=2.66 \times 10^{-27} \mathrm{~kg}$ are boom radius and mass of ion, respectively.
The supply voltage $\varepsilon$ sweeps through a range from 500 to $1000 \mathrm{~V}$ with a step of $100 \mathrm{~V}$ every $2 \mathrm{~s}, 12 \mathrm{~s}$ in 1 set, about 15-18 sets of data are obtained from 300 to $100 \mathrm{~km}$ altitudes in the science experiment-II. The current that is determined by the electrons collected by the boom, emitted from the tape, and the ions collected by the tape is measured in each supply voltage $\varepsilon$. The experimental values are compared with theoretical ones. The total system is rotated about $2 \mathrm{~Hz}$ and it is necessary to obtain the data successively because the current collected by the tape tether and the boom will change depending on the tape face or the boom is in the ram or the wake side of the plasma flow. Maximum current will be $0.1 \mathrm{~A}$, so the required battery power is $100 \mathrm{~W}$.

\section{Conclusions}

In this paper an overview of the S-520-25th project is presented. In particular, it proposes and describes the deployment of the electroconductive bare tape tether, which is the primary mission objective. A new method is shown to be employed for the reliable quick deployment. FAST hollow cathode unit is also presented to be equipped on the sounding rocket as a plasma contactor to demonstrate a bare electrodynamic tether system. Two scientific experiments are presented to obtain new knowledge concerning the electron collection performance of space tether as the first attempt in the world including the performance verification of tape tether and experimental verification of the OML theory. These engineering and scientific demonstrations could open a door for the bare electrodynamic tether, which has a variety of applications in space infrastructures including a propulsion system to increase/decrease orbit, an accelerator and ejector for payload, and an electric power generator. 
Table 3

Preliminary test sequence.

\begin{tabular}{ll}
\hline Time & Operation \\
\hline Several minutes prior to launch & Start purging cathode with xenon flow \\
Several minutes prior to launch & $\begin{array}{l}\text { Start low power cathode heating } \\
\text { Wait for the pressure transducer signal indicating that the atmo- } \\
\text { After the launch }\end{array}$ \\
spheric pressure is reduced to the given level \\
After the pressure transducer signal received & $\begin{array}{l}\text { Start gas purging, ramp-up heater power } \\
\text { About } 2 \text { min after the launch }\end{array}$ \\
\hline
\end{tabular}

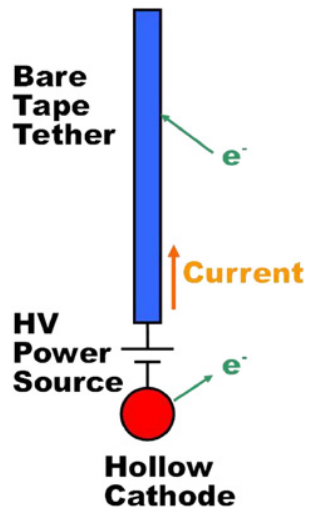

Fig. 14. Scientific experiment-I. Demonstration of electrodynamic tether system by tape tether and hollow cathode.

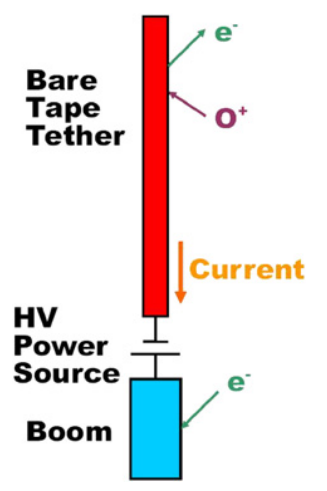

Fig. 15. Scientific experiment-II.

\section{References}

[1] M.L. Cosmo, E.C. Lorenzini, Tethers in space handbook-third edition, Prepared for NASA MSFC by Smithsonian Astrophysical Observatory, Cambridge, MA, 1997.

[2] H.A. Fujii, H. Takegahara, K. Oyama, S. Sasaki, M. Yamagiwa, M. Krujff, E.J. Van der Heide, J. R. Sanmartin, M. Charro, A proposed bare-tether experiment on board a sounding rocket, in: AIAA Guidance, Navigation, and Control Conference and Exhibit, Providence, RI, 2004.

[3] S. Sasaki, K.I. Oyama, N. Kawashima, T. Obayashi, K. Hirano, W.J. Raitt, N.B. Myers, P.M. Williamson, P.M. Banks, W.F. Sharp, Tethered rocket experiment (CHARGE-2): initial results on electrodynamics, Radio Science 23 (6) (1988) 975-988.

[4] B.E. Gilchrist, C. Bonifazi, S.G. Bilen, W.J. Raitt, W.J. Burke, N.H. Stone, J.P. Lebreton, Enhanced electrodynamic tether currents due to electron emission form a neutral gas discharge; results from the TSS-1R mission, Geophysical Research Letters 25 (4) (1998) 437-440.

[5] J.R. Sanmartin, M. Charro, J. Pelaez, I. Tinao, S. Elaskar, A. Hilgers, M. Martinz-Sanchez, Floating bare tether as upper atmospheric probe, Journal of Geophysical Research 111 (11) (2006) A11310.

[6] J.R. Sanmartin, E.C. Lorenzini, Exploration of outer planets using tether for power and propulsion, Journal of Propulsion and Power 21 (3) (2005) 573-576.

[7] M. Kruijff, E.J. van der Heide, F. De Venuto, M. Dobrowolny, G. Vannaroni, Long term stability of bare conductive tethers: combined results from plasuma chamber test and advanced simulator, in: Space Technology and Applications International Forum 2001, Albuquerque, NM, USA, 2001.

[8] T. Ikeda, Y. Nakamura, Y. Yamagiwa, H. Otsu., S. Kawamoto, Y. Ohkawa, A. Nakajima, Multiple bare tethers for electrodynamic tether propulsion, in: Proceedings of the 30th International Electric Propulsion Conference, Florence, Italy, 2007.

[9] T. Watanabe, H.A. Fujii, H. Kojima, Quick deployment of bare tape tether and overview of the sounding rocket experiment, in: Proceedings of the AAS/AIAA Astrodynamics Specialists Conference, Mackinac Island, MI, USA, 2007.

[10] D.D. Tomlin, D.K. Mowery, C.S. Bodley, Tethered satellite system control system design, AIAA 89-1568, in: Proceedings of Third International Conference on Tethers in Space-Towerd Flight, San Francisco, CA, USA, 1989.

[11] J. Carroll, SEDS deployer design and flight performance, AIAA93-4764, in: Space Programs and Technologies Conference and Exhibit, Huntsville, AL, 1993.

[12] S.P.A. van de Heijning, B.T.C. Zandbergen, Design of electrodynamic tape-tether deployment system, IAC-05-C4.6.02, in: 56th International Astronautical Congress of the International Astronautical Federation, Fukuoka, Japan, 2005. 
[13] S.S. Gates, S.M. Koss, M.F. Zedd, Advanced tether experiment deployment failure, in: Proceedings of the AAS/AIAA Astrodynamics Specialist Conference, 1999.

[14] J.D. Williams, B. Rubin, C.C. Farnell. Fast starting hollow cathodes for sounding rocket-based tether experiments, JANNAF-2007, Denver, CO, USA, 2007.
[15] A. Van Dijk., M. Kruijff, E.J. van der Heide, J.P. Lebreton, Lebreton, a lightweight bare rotating tether system for Jovian atmospheric entry, IAC-03-S.P.05, in: 54th International Astronautical Congress of the International Astronautical Federation, 2003, pp. 603-612. 